\title{
Oleanolic Acid, a Pentacyclic Triterpene Attenuates the Mustard Oil-Induced Colonic Nociception in Mice
}

\author{
Juliana Lemos MaiA, ${ }^{a}$ Roberto César Pereira Lima-JÚnior, ${ }^{a}$ Juceni Pereira DAvidD ${ }^{b}$ \\ Jorge Mauricio DAVID ${ }^{c}$ Flávia Almeida SANTOs, ${ }^{a}$ and Vietla Satyanarayana RAO ${ }^{*, a}$ \\ ${ }^{a}$ Department of Physiology and Pharmacology, Faculty of Medicine, Federal University of Ceara; 60430-270 Fortaleza, \\ CE, Brazil: ${ }^{b}$ Pharmacy Faculty, Federal University of Bahia; and ${ }^{c}$ Institute of Chemistry, Federal University of Bahia; \\ 1401-70-250, Salvador, Brazil. Received July 25, 2005; accepted October 25, 2005
}

\begin{abstract}
Many natural terpenoid compounds from plants exhibit antinociceptive property but very few studies have addressed their efficacy in visceral models of nociception. The present study evaluated the antinociceptive potential of oleanolic acid, a pentacyclic triterpene in the mouse model of colonic nociception induced by mustard oil. We further examined the possible participation of opioid, $\alpha_{2}$-adrenergic, and transient receptor potential vanilloid 1 (TRPV1)-receptors in its mechanism. Mice were pretreated orally with oleanolic acid $(3,10,30 \mathrm{mg} / \mathrm{kg}) \mathrm{or}$ vehicle, and the pain-related behavioral responses to intracolonic injection of mustard oil was analysed. Oleanolic acid significantly suppressed the mustard oil-induced nociceptive behaviors at test doses of $10 \mathrm{and} 30 \mathrm{mg} / \mathrm{kg}$, in a dose-related manner. The antinociceptive effect of oleanolic acid $(30 \mathrm{mg} / \mathrm{kg})$ was significantly blocked by pretreatment with the opioid antagonist, naloxone $\left(2 \mathrm{mg} / \mathrm{kg}\right.$, i.p.), while the $\alpha_{2}$-adrenoceptor antagonist, yohimbine $(2 \mathrm{mg} / \mathrm{kg}$, s.c.), had no effect. Pretreatment with ruthenium red $(3 \mathrm{mg} / \mathrm{kg}$, s.c.), a non-competitive TRPV1 antagonist alone caused significant inhibition of mustard oil-induced nociception but its co-administration with oleanolic acid produced neither antagonism nor potentiation of oleanolic acid antinociception. In the open-field test that detects sedative or motor abnormality, mice received $30 \mathrm{mg} / \mathrm{kg}$ oleanolic acid did not show any per se influence, but significantly inhibited the mustard oil-induced decrease in ambulation frequency. These data demonstrate the visceral antinociceptive potential of oleanolic acid that involves an opioid mechanism and possibly a modulatory influence on vanilloid-receptors, which needs further study.
\end{abstract}

Key words oleanolic acid; pentacyclic triterpene; visceral nociception; mustard oil; antinociceptive activity

Visceral pain is the most common form of pain for which the patients often seek medical care. Ascending pathways in the spinal cord that relay nociceptive information from the periphery to supraspinal central nervous system sites has been studied as potential targets for disrupting pain processing and providing relief. Despite the considerable advances in knowledge regarding the basic mechanisms underlying visceral pain and visceral hyperalgesia, no new effective therapies for abdominal pain have been discovered. Tissue injury, inflammation, and algesic chemicals produce changes in the stimulus response, leading to either sensitisation or desensitization of peripheral sensory afferents. An enormous range of pharmacological agents and endogenous substances via numerous receptors influence the visceral afferents. These substances produce their effects on visceral afferents by sensitization, opening of ion channels or by altering the expression of mediators, channels, or receptors. ${ }^{1)}$ In recent years, a central importance is given to capsaicin (vanilloid) receptor 1 (VR1, also called transient receptor potential V1, TRPV1) in the regulation of the activity of sensory afferent nerves. TRPV1 gene knock out mice are analgesic to a wide range of painful inflammatory states, suggesting that TRPV1 receptor antagonists may be effective in those pain states associated with tissue injury, and chemical exposure. ${ }^{2,3)}$ Currently, inflammatory hyperalgesia is managed by NSAIDs (cyclo-oxygenase inhibitors) and opioids, although very effective against inflammatory hyperalgesia, both of these therapeutic classes possess significant limitations. ${ }^{4,5)}$ Opioids induce constipation, and nausea, whereas NSAIDs possess significant side effects on the gastrointestinal, cardiovascular and renal systems.

In the recent past, many novel structures derived from a number of natural sources have been examined for the development of drugs acting as agonists or antagonists at vanilloid receptors, which include compounds like polygodial, a full vanilloid agonist derived from marsh pepper; warburganal from the bark of warburgia trees; isovelleral with terpenoid structure isolated from fungi; scalaradial, an unsaturated dialdehyde isolated from sponges; and scutigeral, isolated from edible mushrooms. ${ }^{6}$ ) The natural triterpenic mixture $\alpha$ - and $\beta$-amyrin, isolated from Protium heptaphyllum has recently been shown to exert gastroprotective effect against ethanolinduced lesions and an antinociceptive effect in the visceral model of nociception induced by capsaicin, possibly involving the capsaicin-sensitive sensory afferents. ${ }^{7,8)}$ Chemically, the $\alpha$ - and $\beta$-amyrin is a mixture of two triterpenes belonging to the ursane ( $\alpha$-amyrin) and oleanane ( $\beta$-amyrin) series. Oleanolic acid is a pentacyclic triterpene that pertains to oleanane ( $\beta$-amyrin) series (Fig. 1) and previous studies established its gastro- and hepato-protective and anti-inflammatory effects. ${ }^{910)}$ So far there have been no available reports that show the efficacy of oleanolic acid in animal models of nociception that would simulate visceral pain in humans.

Intracolonic instillation of capsaicin or mustard oil is a valid model of acute visceral pain in the mouse that evokes

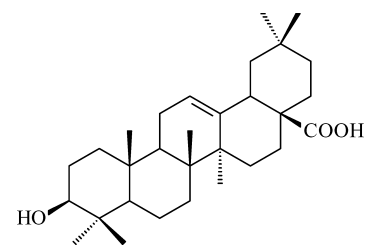

Fig. 1. Chemical Structure of Oleanolic Acid 
spontaneous pain-related behaviors (abdominal licking, stretching, and muscle contractions), simulating the sensations of visceral hyperalgesia (bloating, discomfort and abdominal pain) often experienced by patients with IBS or other functional disorders. ${ }^{11,12)}$ The present study aimed to assess the antinociceptive potential of oleanolic acid and its possible mechanism, using the mouse model of acute colonic nociception induced by mustard oil.

\section{MATERIALS AND METHODS}

Plant Material The aerial parts $(2.4 \mathrm{~kg})$ of Eriope blanchetii (BENTH.) HARLEY (Lamiaceae) was collected from the Metropoliton Park area of Abaeté (Salvador, BA) after its identification and the voucher specimen (\#045599) was retained in Alexandre Leal Costa Herbarium, Institute of Biology, Federal University of Bahia. Oleanolic acid was extracted and isolated from the dried plant material as per procedures described earlier. ${ }^{13)}$ In brief, the ground plant material was first macerated with $\mathrm{MeOH}$ and the crude methanolic extract was concentrated and partitioned between hexane: $\mathrm{MeOH} / \mathrm{H}_{2} \mathrm{O}(9: 1), \mathrm{CHCl}_{3}: \mathrm{MeOH} / \mathrm{H}_{2} \mathrm{O}(6: 4)$ and AcOEt: $\mathrm{H}_{2} \mathrm{O}(6: 4)$. The chloroformic phase was then submitted to fractionation on silica gel column chromatography using the mixtures of $\mathrm{CHCl}_{3}: \mathrm{MeOH} / \mathrm{H}_{2} \mathrm{O}$ in increasing polarity and the fractions obtained were purified by repeated chromatography and methylation processes so as to obtain pure methyl ester of oleanolic acid (2.5 g). The oleanolic acid was identified based on spectral data obtained from NMR IV $\left({ }^{1} \mathrm{H}\right.$ and $\left.{ }^{13} \mathrm{C}\right)$, and Mass Spectrometry and in comparison with literature data. For experiments, oleanolic acid was suspended in aqueous Tween 80 solution ( $2 \%)$.

Chemicals The chemicals used in the study were the mustard oil, ruthenium red, morphine, naloxone, clonidine and yohimbine (Sigma-Aldrich, Brazil). All drugs were dissolved in saline.

Animals Experiments were performed on male Swiss albino mice $(22-26 \mathrm{~g})$ obtained from the Central Animal House of this University and the Institutional Animal Care and Use Committee approved the experimental protocols, which were in accordance with the ethical guidelines of International Association for the Study of Pain (IASP).

Mustard Oil-Induced Colonic Nociception To assess the antinociceptive effect of oleanolic acid against the mustard oil (MO)-induced colonic nociception, mice in groups $(n=8)$ were orally treated with oleanolic acid $(3,10$ or $30 \mathrm{mg} / \mathrm{kg}$ ), vehicle ( $2 \%$ Tween 80 in distilled water) or morphine $(5 \mathrm{mg} / \mathrm{kg}$, s.c.), $1 \mathrm{~h}$ and $30 \mathrm{~min}$, respectively, before the intracolonic administration of MO (Sigma-Aldrich, Brazil; $0.75 \%$ in saline $0.9 \%, 50 \mu \mathrm{l} /$ animal $).{ }^{11)}$ A group of normal controls received a similar volume of saline $(10 \mathrm{ml} / \mathrm{kg}) . \mathrm{Im}$ mediately following the intracolonic MO or saline administration, the mice were observed for the total number of nociceptive behaviors (licking the upper abdomen, stretching the abdomen, squashing the abdomen against the floor and retraction of the abdomen characterized for an arched position), for a $20 \mathrm{~min}$ period. Behavioral study was performed by personnel blind to the drug treatments and each animal was used only once for the experimentation. In order to verify the possible mechanisms in the antinociceptive effect of oleanolic acid, mice were pretreated with the opioid antago- nist, naloxone $\left(2 \mathrm{mg} / \mathrm{kg}\right.$, i.p.), the $\alpha_{2}$-adrenoceptor antagonist, yohimbine $(2 \mathrm{mg} / \mathrm{kg}$, s.c.), or the TRPV1 antagonist, ruthenium red $(3 \mathrm{mg} / \mathrm{kg}$, s.c.), alone or in combination with oleanolic acid $(30 \mathrm{mg} / \mathrm{kg})$ or morphine $(5 \mathrm{mg} / \mathrm{kg}$, s.c.) or clonidine $(100 \mu \mathrm{g} / \mathrm{kg})$. Antagonists were administered $15 \mathrm{~min}$ before the administration of oleanolic acid or the agonists, morphine or clonidine. Sixty minutes after oleanolic acid or 30 min following morphine and clonidine administrations, MO test was carried out as described earlier. Saline treated controls (normal) that did not receive $\mathrm{MO}$ and vehicletreated controls that received MO were also included.

Behavior in Open-Field Test Mice were observed for locomotion in an open-field apparatus. Each mouse was observed for the locomotion frequency (number of floor units the animal entered with all its limbs) was counted for a period of $4 \mathrm{~min}$, following $60 \mathrm{~min}$ of oral administration of oleanolic acid $(30 \mathrm{mg} / \mathrm{kg})$, intracolonic MO $(0.75 \%, 50 \mu \mathrm{l})$ or vehicle ( $2 \%$ Tween 80 in distilled water, p.o. $){ }^{14)}$

Statistical Analysis The results are expressed as mean \pm S.E.M. from 6-8 mice per group. For statistical analysis, ANOVA followed by Dunnett's or Student Newman Keul's post hoc test, as appropriate were used. A $p<0.05$ was considered statistically significant.

\section{RESULTS}

Figure 2 depicts the antinociceptive effect of oleanolic acid in mustard oil test. Intracolonic application of $\mathrm{MO}$ $(0.75 \%, 50 \mu \mathrm{l})$ provoked a significant increase in spontaneous pain-related behaviors when compared with saline treated normal controls. The dose selection of MO for this test was based on our preliminary experiments that showed good consistency in producing pain-related behaviors. In groups pretreated with oleanolic acid $(10,30 \mathrm{mg} / \mathrm{kg}$, p.o.), mustard oil-induced nociceptive behaviors were significantly inhibited in a dose-related manner. The visceral pain-related behaviors-evoked by MO were significantly suppressed in groups of mice pretreated with morphine $(5 \mathrm{mg} / \mathrm{kg}$, s.c.), an $\alpha_{2}$-adrenoceptor agonist clonidine $(0.1 \mathrm{mg} / \mathrm{kg}$, i.p.) or the TRPV1 non-competitive antagonist ruthenium red $(3 \mathrm{mg} / \mathrm{kg}$, s.c.) (Figs. 2-4). The suppressive effects of triterpene mix-

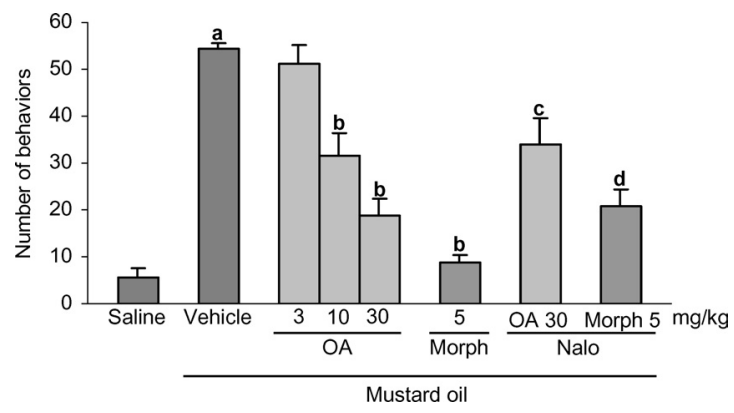

Fig. 2. The Antinociceptive Effect of Oleanolic Acid against Mustard OilInduced Visceral Nociception and the Possible Involvement of Opioid-Receptor, in Mice

Pain-related behaviors (licking of abdomen, stretching, abdominal retractions)evoked by intracolonic mustard oil $(0.75 \%, 50 \mu 1)$ instillation were observed in the $20 \mathrm{~min}$ post-administration in mice pre-treated with vehicle $(2 \%$ Tween 80 in distilled water, p.o.), oleanolic acid (OA, 3, 10, 30 mg/kg, p.o.), morphine (Morph, $5 \mathrm{mg} / \mathrm{kg}$, s.c.), naloxone (Nalo, $2 \mathrm{mg} / \mathrm{kg}$, i.p.) $+\mathrm{OA}(30 \mathrm{mg} / \mathrm{kg})$ or Nalo + Morph. Data represent the mean \pm S.E.M. $(n=8)$. ${ }^{\mathrm{a}} p<0.01 v s$. saline; ${ }^{\mathrm{b}} p<0.01 v \mathrm{~s}$. vehicle-treated group that received mustard oil; ${ }^{\mathrm{c}} p<0.05$ vs. OA; ${ }^{\mathrm{d}} p<0.05 v s$. Morph. 


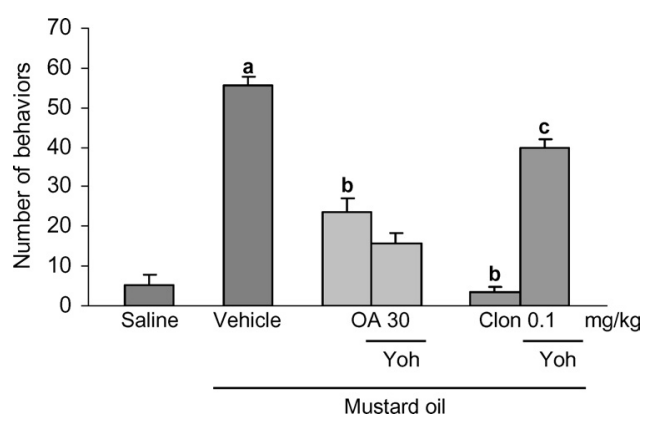

Fig. 3. Effect of $\alpha_{2}$-Adrenoceptor Antagonism on the Antinociceptive Effect of Oleanolic Acid in Mustard Oil Test

Behaviors related to pain after intracolonic instillation of mustard oil $(0.75 \%$ in saline $0.9 \%, 50 \mu \mathrm{l})$ were observed in groups of mice pre-treated with vehicle $(2 \%$ Tween 80 in distilled water, p.o.), oleanolic acid (OA, $30 \mathrm{mg} / \mathrm{kg}$, p.o.), yohimbine (Yoh, $2 \mathrm{mg} / \mathrm{kg}$, s.c. $)+\mathrm{OA}$ or clonidine $(\mathrm{Clo}, 0.1 \mathrm{mg} / \mathrm{kg}$, i.p. $)+$ Yoh. Data represent the mean \pm S.E.M. $(n=8) .{ }^{a} p<0.01 v s$. saline; ${ }^{b} p<0.01 v s$. vehicle; ${ }^{c} p<0.01 v s$. Clo.

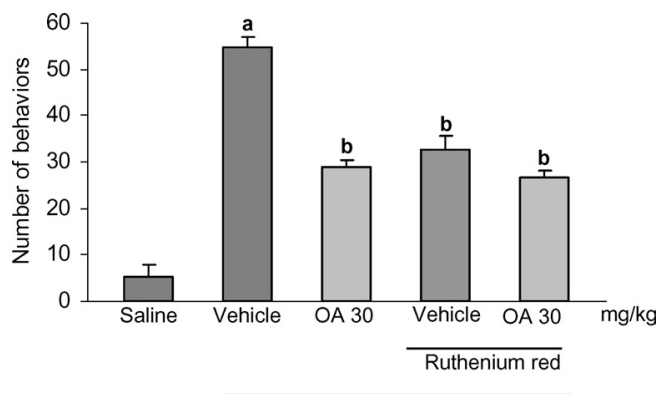

Mustard oil

Fig. 4. Possible Involvement of TRPV1 (Vanilloid)-Receptor in the Antinociceptive Effect of Oleanolic Acid in Mustard Oil Test

Pain-related behaviors after intracolonic instillation of mustard oil $(0.75 \%$ in saline $0.9 \%, 50 \mu \mathrm{l} / \mathrm{animal})$ were observed in groups of mice pre-treated with vehicle $(2 \%$ Tween 80 in distilled water, p.o.), oleanolic acid (OA $30 \mathrm{mg} / \mathrm{kg}$, p.o.), ruthenium red $(3 \mathrm{mg} / \mathrm{kg}$, s.c. $)$ or ruthenium red + OA. Data represent the mean \pm S.E.M. $(n=8)$ ${ }^{\mathrm{a}} p<0.01 \mathrm{vs}$. saline; ${ }^{\mathrm{b}} p<0.01 \mathrm{vs}$. vehicle-treated group that received mustard oil.

Table 1. Effect of Oleanolic Acid on Mouse Behavior in Open-Field Test

\begin{tabular}{ll}
\hline \hline \multicolumn{1}{c}{ Group } & $\begin{array}{c}\text { Locomotion } \\
\text { frequency }\end{array}$ \\
\hline Vehicle & $47.00 \pm 4.53$ \\
OA $(30 \mathrm{mg} / \mathrm{kg}$, p.o. $)$ & $44.67 \pm 2.11$ \\
Vehicle $+\mathrm{mustard}$ oil & $28.00 \pm 2.59^{*}$ \\
OA $(30 \mathrm{mg} / \mathrm{kg}$, p.o. $)+$ mustard oil & $50.50 \pm 7.44^{* *}$ \\
\hline
\end{tabular}

Mice were pre-treated with vehicle ( $3 \%$ Tween 80 in distilled water, p.o.) or oleanolic acid (OA, $30 \mathrm{mg} / \mathrm{kg}$, p.o.), before the intracolonic instillation of saline or mustard oil $(0.75 \%, 50 \mu \mathrm{l})$. Data represent the mean \pm S.E.M. $(n=6) . * p<0.05 v s$. vehicletreated group; $* * p<0.05 v s$. vehicle + mustard oil.

ture $(30 \mathrm{mg} / \mathrm{kg})$ and morphine were in part reversed by naloxone $(2 \mathrm{mg} / \mathrm{kg}$, s.c. $)$, a non-selective opioid antagonist (Fig. 3). Yohimbine, the $\alpha_{2}$-adrenoceptor agonist could reverse the antinociception produced by clonidine only but not of oleanolic acid (Fig. 3). The ruthenium red neither potentiated nor antagonised the anti-nociceptive response of oleanolic acid (Fig. 4). In open-field test, intracolonic MO caused a significant inhibition on the locomotor activity in mice (Table 1). Oleanolic acid $(30 \mathrm{mg} / \mathrm{kg}$, p.o. $)$ manifested no per se effect on locomotor frequency, but showed complete reversal of MO-induced hypolocomotion.

\section{DISCUSSION}

In animals several algogenic substances like capsaicin, mustard, and cyclophosphamide, applied to visceral structures can elicit pain-related behaviors involving capsaicinsensitive primary afferents [Maggi et al., 1992]. ${ }^{15-17)}$ These algogenic substances are capable of inducing pain as well as inflammatory reaction when either visceral afferents are sensitized or central neurons undergo a change in excitability (central sensitization) after persistent visceral input. ${ }^{18)}$ In the search for novel natural substances, which possess visceral antinociceptive property, we used the acute model of visceral pain induced by intracolonic instillation of MO to produce spontaneous pain-related behaviors in mice (abdominal licking, stretching, and muscle contractions), which has diseaserelevancy to human irritable bowel syndrome. ${ }^{11)}$ The triterpenoid oleanolic acid could significantly suppress the painrelated behaviors against mustard oil-induced visceral pain, possibly regulating the functioning of primary afferent fibers. Visceral afferents express a wide range of membrane receptors (including vanilloid receptors, TRPV1) to chemical stimuli, which are involved in sensory signalling from the gut to the central nervous system. ${ }^{19)}$ Figure 4 shows that both ruthenium red and oleanolic acid could inhibit the MO-induced nociception almost to the same extent. However, it does not imply that oleanolic acid is a non-competitive antagonist of TRPV1 like, ruthenium red. Moreover, when animals were pretreated with these agents (oleanolic acid and ruthenium red) in combination, there was no antagonism or additive antinociception in mustard oil test. Also, unlike capsaicin, oleanolic acid failed to induce per se nociception following subplantar injection into the mouse hind paw (data not shown). These observations suggest that the oleaonolic acid does not act as a TRPV1 agonist but may possibly induce a modulatory influence on vanilloid-receptors, which needs further clarification. Past works have shown that MO can induce acute colitis and oleanolic acid has been reported to exert anti-inflammatory action. ${ }^{20,21)}$ Therefore it is reasonable to assume that oleanolic acid suppresses the inflammatory pain. The $\alpha_{2}$-adrenoceptor agonist has been shown to induce antinociceptive effect in the experimental model of formalin-induced colitis in rats and reduce visceral hypersensitivity in clinical settings. ${ }^{22,23)}$ Therefore, a possible involvement of $\alpha_{2}$-adrenoceptors in the antinociceptive effect of oleanolic acid in MO-model of colitis, using the agonist clonidine and the antagonist yohimbine. The results obtained indicate that both clonidine and oleanolic acid were able to suppress the pain-related behaviors. However, yohimbine could reverse the antinociception produced by clonidine but not of oleanolic acid, suggesting that $\alpha_{2}$-adrenoceptors play no role.

It has been suggested that $\kappa$-opioid receptors are more strongly linked with visceral pain. ${ }^{24)}$ In the present study, morphine significantly suppressed the visceral pain more efficiently than oleanolic acid probably due to lack of $\kappa$-opioid agonistic activity. Nevertheless, the antinociception induced by both morphine and oleanolic acid was found to be naloxone-sensitive, indicating the involvement of opioid receptors. Oleanolic acid, at the dose that produced inhibition of MOnociception did not impair locomotion of mice in open-field test. Interestingly, oleanolic acid could effectively reverse the 
mustard oil-induced hypolocomotion in this test, suggesting that the oleanolic acid alleviates MO-induced visceral pain. In conclusion, the data obtained on oleanolic acid indicate that the triterpene oleanolic acid inhibits visceral nociception through an opioid mechanism. Further, it may have a modulatory influence on vanilloid receptors, which needs further elucidation on its antinociceptive activity.

Acknowledgment The authors are grateful to $\mathrm{CNPq}$ (Proc. No. 300108) for financial support.

\section{REFERENCES}

1) Collins S., Gut, 53 (Suppl. II), 19-21 (2004).

2) Davis J. B., Gray J., Gunthorpe M. J., Hatcher J. P., Davey P. T., Harries M. H., Latcham J., Clapham C., Atkinson K., Hughes S. A., Rance K., Grau E., Harper A. J., Pugh P. L., Rogers D. C., Bingham S., Randall A., Sheardown S. A., Nature (London), 405, 183-187 (2000).

3) Caterina M. J., Leffler A., Malmberg A. B., Martin W. J., Trafton J., Petersen-Zeitz K. R., Koltzenburg W. J., Basbaum A. I., Julius D., Science, 288, 306-313 (2000).

4) Ji R. R., Zhang Q., Law P. Y., Low H. H., Elde R., Hokfelt T., J. Neurosci., 15, 8156-8166 (1995)

5) Mansour A., Fox C. A., Akil H., Watson S. J., Trends Neurosci., 18 22-29 (1995).

6) Sterner O., Szallasi A., Trends Pharmacol. Sci., 20, 459-465 (1999).

7) Oliveira F. A., Vieira-Junior G. M., Chaves M. H., Almeida F. R. C., Santos K. A., Martins F. S., Silva R. M., Santos F. A., Rao V. S. N.,
Planta Med., 70, 780-782 (2004).

8) Oliveira F. A., Costa C. L., Chaves M. H., Almeida F. R. C., Cavalcante I. J., Lima F., Lima-Júnior R. C. P., Silva R. M., Santos F. A., Rao V. S. N., Life Sci., (2005) (in press).

9) Singh G. B., Singh S., Bani S., Gupta B. D., J. Pharm. Pharmacol., 44, 456-458 (1992).

10) Rodriguez J. A., Astudillo L., Schmeda-Hirchmann G., Pharmacol. Res., 48, 291-294 (2003).

11) Laird J. M. A., Martinez-Caro L., Garcia-Nicas E., Cervero F., Pain, 92, 335-342 (2001).

12) Mayer F. A., Gebhart G. F., Gastroenterology, 107, 271-293 (1994).

13) David J. P., Da Silva E. F., De Moura D. L., Guedes M. L. S., Assunção R. J., David J. M., Quim. Nova., 24, 730-733 (2001).

14) Capaz F. R.,Vanconcellos L. E. M., De Moraes S., Neto J. P., Archiv Intern. Farmacodyn., 25, 228-236 (1981).

15) Maggi C. A., Lecci A., Santicioli P., Del Bianco E., Auton. Nerv. Syst., 38, 201-208 (1992)

16) Kobayashi Y., Planta Med., 69, 425-428 (2003).

17) Jordt J. E., Bautista D., Chuang H. H., Mckemy D. D., Zygmunt P. M., Hogestatt E. D., Meng I. D., Julius D., Nature (London), 427, 260265 (2004).

18) Jiang M. C., Gebhart G. F., Pain, 77, 305-313 (1998).

19) Wood J. N., Gut, 53, ii9-12 (2004).

20) Kimball E. S., Palmer J. M., D’Andrea M. R., Hornby P. J., Wade P. R., Am. J. Physiol. Gastroenterol., 288, G1266-1273 (2005).

21) Kapil A., Sharma S., J. Pharm. Pharmacol., 47, 585-587 (1995).

22) Miampamba M., Chery-Croze S., Detolle-Sarbach S., Guez D., Chayvialle J. A., Eur. J. Pharmacol., 308, 251-259 (1996).

23) Blackshaw L. A., Gebhart G. F., Curr. Opin. Pharmacol., 6, 642-649 (2002).

24) Black D., Trevethick M., Gut, 43, 312-313 (1998). 